\title{
Ressonàncies musicals en l'obra de Fontanella
}

\author{
Musical echoes in Francesc Fontanella's works
}

\author{
Josep Pujol i Coll \\ josep.pujol@esmuc.cat \\ Escola Superior de Música de Catalunya (ESMUC)
}

Resum: En referència a la poesia de Francesc Fontanella, l'article assenyala primerament la presència del compositor Joan Cererols com a poeta en català al seu Vexamen, una dada que ha passat inadvertida en els cercles musicològics. Seguidament fa un recompte de les poesies de Fontanella amb vincles musicals, sobretot amb els vilancets. Per últim, recupera algunes melodies que, com a contrafacta, encaixen amb les seves lletres per a cantar.

Paraules clau: Francesc Fontanella, segle XVII, música, cançoners, contrafacta.

Abstract: Referring to the Francesc Fontanella's poetry, the article first notes the presence of the composer Joan Cererols as a poet in Catalan at his Vexamen, a fact that has gone unnoticed in musicological circles. Then it links the poetry of Fontanella with musical genres, especially with the villancicos. Finally, it retrieves some melodies that, as contrafacta, fit with his lyrics to sing them.

Keywords: Francesc Fontanella, 17th century, music, songbooks, contrafacta. 


\section{Josep Pujol i Coll. Ressonàncies musicals en l'obra de Fontanella}

\section{Introducció}

Els col loquis dedicats a les confluències i les relacions interdisciplinàries solen aportar agradables sorpreses, confinats com solem estar en les nostres parcel les especialitzades. En el cas de la música i la literatura -i encara més en el barroc-, aquestes trobades encara es fan més necessàries, perquè estan en contínua relació. Pocs musicòlegs deuen saber que Joan Cererols (1618-1680), el gran compositor montserratí, apareix al Vexamen de Fontanella, llarga sàtira acadèmica en vers, freqüents a les acadèmies del barroc ${ }^{1}$. El Vexamen de Francesc Fontanella (1622-1682/1683), que va tenir lloc al Convent de Santa Caterina de Barcelona el 1643, es va produir com a culminació de les festes de la rebuda d'una relíquia de Sant Tomàs, durant vuit dies de festa «ab tota la ostentació de música y altres instruments festius». El Vexamen va durar unes dues hores perquè «de tant en tant tocaven una companyia de menestrils que y havia en lo chor» (Brown 1987: 176). El 1643 Cererols era un jove monjo novici de 25 anys encara en formació, abans que la completés al Montserrat madrileny, i sorprèn que aparegui al Vexamen no com a mestre de capella o ministril, sinó com a poeta en llengua catalana al costat d'altres poetes «llunàtics» (Brown 1987: vv. 561-564):

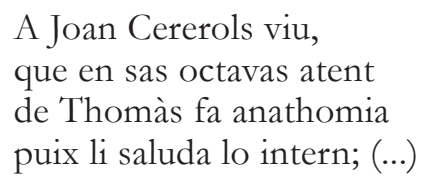

Un cop endinsats en l'obra de Fontanella, les sorpreses musicals continuen. Abans que res, tanmateix, hauríem de separar les ressonàncies musicals que apareixen als seus poemes més aviat com a recursos o formulismes que no impliquen necessàriament una realitat musical de les que sí que ho fan. És a dir, sembla improbable que la «Cançó» que apareix inserida en l’ègloga Era del dia aquella edat primera hagi tingut alguna vegada cap melodia, excepte la que forma la prosòdia dels mateixos versos. Així, la «ronca lira» de què s'acompanya Fontano és purament literària.

Altrament, ens quedaríem curts si consideréssim exclusivament com a musicals els poemes que l'editora Maria-Mercè Miró, organitzant l'obra de Francesc Fontanella (Miró 1995), bateja com a «lletres per a cantar», repartides per diverses seccions (al final de la poesia amorosa, subdividida en les poesies a Nise i Elisa i les Giletes; enmig de la poesia religiosa i de nou al final de la poesia satírica i jocosa). És ben segur, d'entrada, que els goigs a Santa Magdalena i a Santa Rosa també estaven pensats per ser cantats, vés a saber amb quina melodia del grapat que s'usaven i reutilitzaven per als goigs, algunes de les quals han arribat als nostres dies. I explícitament duia música el drama religiós Veniu del Líbano de la puresa, per a l'Assumpció de la Verge, gairebé un petit oratori, tot i que els

1 Almenys, la biografia de Gregori Estrada al darrer volum de l'obra completa de Cererols no en fa esment (Estrada 1981: IX-XXV), tampoc les darreres aportacions de Ferran Balanza (1985: 25-76). La dada puntual, a més, és interessant perquè informa d'alguns anys en blanc de la vida del compositor, de qui sabem només que estava en formació al monestir. De la mateixa època se n'ha conservat una dedicatòria a la Verge de Montserrat que testimonia el seu coneixement humanístic de la llengua llatina (Estrada 1981: nota 5). 


\section{Josep Pujol i Coll. Ressonàncies musicals en l'obra de Fontanella}

primers oratoris entesos com a tals no arriben a Catalunya fins a la segona meitat del XVII.

Per tant, les poesies «per a cantar» de Fontanella ben segur que s'amplien força més de les que així s'expliciten en l'obra editada per Miró ${ }^{2}$ :

\begin{tabular}{|c|l|}
\hline «lletres per a cantar»: & \\
\hline Poesia amorosa, I & 7 lletres \\
\hline Poesia amorosa, II (Gileta) & 1 lletra \\
\hline Poesia religiosa & 46 lletres \\
\hline Poesia satırica ijocosa & 7 lletres \\
\hline Goigs & 61 «lletres per a cantar» \\
\hline Drama religiós & 2 \\
\hline Nadales dialogats & 1 \\
\hline Vilancets dial & 11 \\
\hline & 4 \\
\hline
\end{tabular}

\section{Els vilancets de Fontanella}

Eren vilancets o villancicos les peces literàrio-musicals que es cantaven dins les esglésies al final de les cerimònies religioses en determinades festivitats, no només per Nadal (Knighton/Torrente 2007). Molt sovint se n'interpretava més d'un, això explicaria que certes «lletres per cantar» vagin agrupades al mateix assumpte, sigui a la Puríssima Concepció, sigui pel Santíssim Sagrament (segurament per Corpus) o a algun sant. De vilancets, és clar, n’hi havia per a les festes de Nadal, d'aquí els onze conservats. No és gens descabellat pensar que totes aquestes lletres per cantar o vilancets hagin estat musicats per algun mestre de capella; potser, com suggereix Maria-Mercè Miró (1995: 78), que fossin encarregades pels superiors dels dominicans o quan Fontanella fou prior al convent de Perpinyà. Era una tasca que, amb un cert sentit de l'especialització literària, solien redactar els «poetes vilanciquers», dels quals tenim nombroses mostres produïdes pel saragossà Vicente Sánchez, el castellà Manuel de León Marchante o el valencià José Pérez de Montoro, entre altres. Fins i tot Góngora fou poeta villanciquero per a determinades festivitats (Pujol Coll 2016: 58-74).

L'estructura formal dels vilancets del segle XVII subdividia el text en una tornada inicial («estribillo», A) i un seguit d'estrofes, molt sovint quartetes («coplas», B). L'estribillo era present, almenys, al principi i al final del vilancet (A BBBB... A), però també podia arribar a repetir-se entre estrofa $i$ estrofa (A BA BA BA ...) o després d'un grup d'estrofes (A BBA BBA ...). Són esquemes formals que s'adapten a moltes de les lletres per cantar de Fontanella. L'estribillo tenia més desenvolupament musical que literari; les coplas, en canvi, estaven al servei del text i solien repetir la mateixa melodia (Bègue 2001: 134). Per tant, les tornades que tanquen moltes «lletres per a cantar» de Fontanella, en la seva versió musical podrien ser estribillos musicals i estar inserits, en realitat, a l'inici de la peça, o com una represa enmig de les estrofes.

2 A l'espera que es completi l'edició crítica electrònica de l'obra poètica (Fontanella 2017), encara s'utilitza bàsicament l'edició de M. Mercè Miró per al recompte i els títols de les obres. 


\section{Josep Pujol i Coll. Ressonàncies musicals en l'obra de Fontanella}

Les nadales presenten trets en comú amb les lletres per a cantar religioses. Excepte alguna, el seu lloc sembla estar dins les esglésies, a les matines de Nadal, que era quan la capella musical solia interpretar-los. Entre funestas rü̈nas, a més, fa ús d'un tòpic molt freqüent en els vilancets musicals barrocs, la recreació de personatges ètnics caracteritzats mitjançant la seva parla, en aquest cas el «llenguatje diferent» es tracta de pastors portuguesos. En aquestes peces popularitzants, el Portal s'omple de negres, portuguesos, biscaïns, francesos, gascons, cadascun amb un argot estrafet que li és característic (Pujol Coll 2016: 136-138). Així mateix són recurrents les interjeccions musicals falaralà, falaralà; dirín, dirín o faralà, faralà, ra, rena, presents en les cançons populars però també en els vilancets d'estil popularitzant compostos a mitges entre poetes vilanciquers i mestres de capella.

També són evidentment nadalencs els «Villancets dialogats», que s'organitzen com a petites peces dramàtiques, freqüents en la música devocional del XVII i XVIII. Si a Ola, pastors de Bel Vem hi trobem un duo amb la intervenció del cor, els solistes augmenten fins a quatre a Què as, què as vist, o pastor!, també amb el cor puntejant-los. Un altre duo, La neu de esta montanya, combina recitació i música, i Dichosos y bumils pastors especifica que cal cantar-lo al to de madama de Ricort. Això implica que, com la resta de lletres per a cantar «al to de» van reutilitzar músiques ja conegudes.

\section{Les lletres per a cantar «al to de»}

Algunes «lletres per a cantar» de Fontanella s'encapçalen amb l'expressió «al to de» o similar en alguns dels manuscrits. El procediment de reutilitzar la melodia d'una cançó per aplicar-la a una altra, conegut com a contrafactum, té una llarga tradició des de l'època medieval. Durant el barroc la trobem en molts cançoners, que així no han de recórrer ni a la creació de noves tonades ni a cap partitura per deixar-ne constància. Hi apareixen sovint les expressions «al to de», «es canta al to de» o similar, esmentant una tonada que sigui prou coneguda -si més no en el seu temps-i que, és clar, encaixi en síl labes i versos en la nova proposta. En el cas de les lletres per a cantar de Fontanella, hi trobem citades les següents tonades:

\begin{tabular}{|c|c|}
\hline 80. Amaranta. la nimfa més bella & «Maracipalos», «Marisapalos» \\
\hline 76. Cristaling campanye & "Lletra al to de Gigante Cristalino» \\
\hline 162. Belisa de les Giletas & "Lletra al to de Aver Angélica supe» \\
\hline 256. Sentiu gran pena & "To de la ministranda» \\
\hline 257. La lerge pura. & «To de la ministranda»" \\
\hline 265. Dichosos y bumils pastors & $\begin{array}{l}\text { «So de madama de Ricort» } \\
\text { «To de madama de Ricort» } \\
\text { «To de madama Ricort» }\end{array}$ \\
\hline
\end{tabular}

A banda d'aquestes referències escrites de contrafacta, se n'hi pot afegir una altra de transmissió oral: els decasíl labs de En primavera se múdan les iras (núm. 253) es podrien haver cantat al to d'El Noi de la Mare (Miró 1995: 80). La mètrica ho permet al llarg de tota la peça, encaixant-hi a la perfecció. 
Mitjançant el contrafactum, el grup de música i dansa antiga i tradicional Xuriach ${ }^{3}$ ha pogut interpretar Amaranta, la nimfa més bella, aprofitant que un parell de manuscrits conservats posaven com a títol aquesta peça Maracipalos o Marisapalos. La Mariqápalos va ser una de les cançons més conegudes i difoses per tota la Península, versionada i reversionada en els repertoris de guitarristes, arpistes i teclistes fins ben entrat al segle XVIII. El text inicial de la cançó «Marizápalos bajó una tarde / al fresco Sotillo de Vaciamadrid.... es va distribuint en estrofes de quatre versos que encaixen prou amb el poema de Fontanella. ${ }^{4}$

Cristalina campanya, datada potser a l'entorn de 1650, sembla tenir una certa consonància amb el to amb el qual s'hauria de cantar, Gigante cristalino. En aquest cas tornem a tenir sort, ja que és un tono relativament conegut i ben estudiat per la doctora Lola Josa, que juntament amb el musicòleg Mariano Lambea i Francisco Valdivia han fet una feina interdisciplinar excel lent relacionant música i poesia del segle XVII (Lambea/Josa/Valdivia 2012). Gràcies al seu estudi sabem que Gigante cristalino és un to amb la música de Manuel Correa i la lletra de Lope de Vega extreta de l'obra La Dorotea. Fou molt divulgat a l'època, ja que els estudiosos del NIPEM n'han trobat fins a deu fonts 5 . Si l'agafem tal com apareix al recull cabdal per a la música hispànica del segle XVII, el Libro de Tonos Humanos (Lambea/Josa 2005: 292-294), se'n pot elaborar el contrafactum, aplicant-hi la lletra de Fontanella, per exemple, a la veu de la soprano:

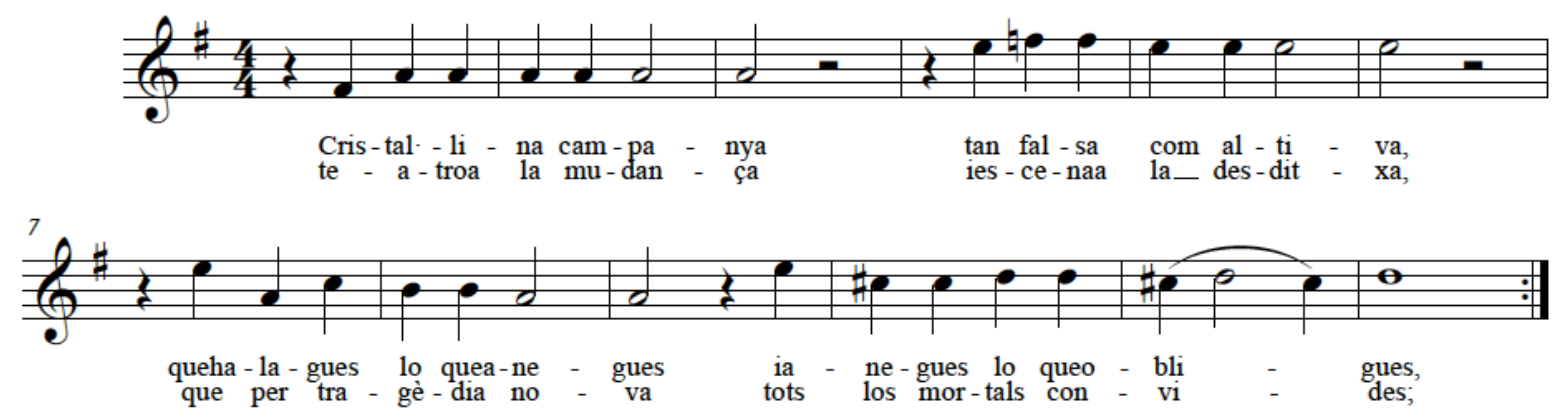

Hi hauria d'altres possibilitats, com una versió que mantingués la polifonia de les quatre veus del tono de Correa. L'original té a més a més una tornada de tres versos que es repetiria entre estrofa i estrofa, i que Fontanella no sembla aprofitar.

Belisa de las Giletas és l'única lletra per a cantar de la sèrie amorosa de joventut de Fontanella, dedicada a

3 Web pròpia a <http:/ /www.xuriach.com>, tot i que la seva versió de la Marizápalos aplicada a Amaranta, la nimfa més bella no hi apareix, ni n’han publicat cap enregistrament [consulta: abril 2018].

4 Per a un resum de les fonts de Marizápalos i la seva transcripció bàsica, veure Russell 1999.

5 A més de les assenyalades, se n’hi pot afegir la del vilancet de negres Tolibiyo, Baltolo cantat durant la nit de Nadal a la catedral de Toledo el 1655, on fa una reutilització parcial del tono de Correa, enmig d'altres (Pujol Coll 2016: 129-131). 


\section{Josep Pujol i Coll. Ressonàncies musicals en l'obra de Fontanella}

la jove Gileta, identificada amb Maria Teresa Ham, de Perpinyà. Només un manuscrit indica «Lletra al to de Ayer Angélica supe». Gairebé per casualitat puc aportar la troballa de la melodia d'aquest to -per bé que incompleta-, elaborant la meva tesi doctoral. D’entrada, l'Angélica esmentada té ressons de Góngora i Ariosto. Góngora, gran llegidor de l'Orlando furioso de Ludovico Ariosto, va recrear-ne un episodi al Romance de Angélica y Medoro (1602). S'hi narren els amors de la princesa Angélica i el pastor Medoro, una història de gelosia ja que el comte Orlando n’està enamorat. Però aquest romanç de Góngora no conté l'expressió «Ayer Angélica supe», per tant sembla que n’és una paràfrasi anònima.

Tanmateix, transcrivint el vilancet «de negres» Al Chicorrotiyo, de Juan de la Bastida, vaig poder constatar que s'hi esmentaven i reutilitzaven diversos tons tàcitament coneguts a l'època ("Señora Inés», «Don Pedro a quien los crueles», «Ayer, Angélica, supe», «Mandan que salgan de Roma» i «Esquiva, adorada Europa») (Pujol Coll 2016: 129-131). El text es conserva en un fulletó datat al 1700, així com en una partitura al Monestir de l'Escorial, de Juan de la Bastida ${ }^{6}$. A les cobles, després que el cor pregunti «Qué tonadilla me escogeré?», en comptes de repetir-s'hi la mateixa melodia -com és habitual als vilancets-, els solistes les varien cantant-hi fragments dels tons esmentats. I a la tercera copla el tenor canta, en l'artificiosa parla 'negra' -no deixa de ser un villancico de negros-, un fragment de Ayer, Angélica, supe:

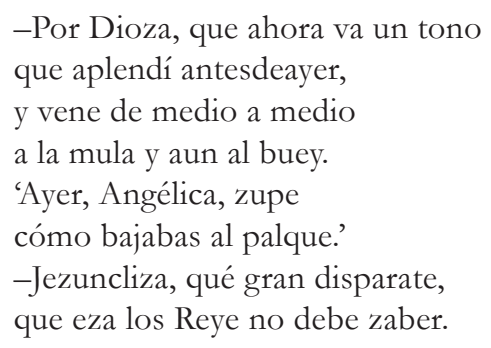

I sí, la melodia amb què canta «Ayer Agélica, supe / cómo bajabas al parque» encaixa amb els dos primers heptasíl labs de Belisa de las Giletas, però no pas sense alguna violència accentual:

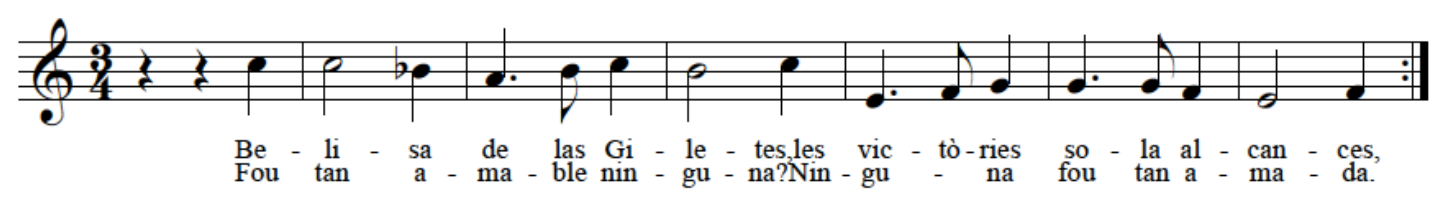

Sentiu gran pena i La Verge pura assenyalen que s'han de cantar «al to de la ministranda». Segurament devia ser una tonada popular coneguda, coetània, moderna, i que devia adaptar-se prou bé a la

6 Real Biblioteca del Monasterio del Escorial (Madrid), sig. 18-6. 


\section{Josep Pujol i Coll. Ressonàncies musicals en l'obra de Fontanella}

mètrica i a l'estil del poema, en remarcar-s'hi «Cantem lletretes,/ tonadas pastorils, / ab moderns tons / que sían bons».

Hi ha una sola font musical on ha deixat rastre aquesta Ministranda. Es tracta d'un manuscrit de mitjans del XVII que recull diverses danses, entre elles algunes sardanes, fet que l'han convertit en una font molt interessant. Es tracta del llibre Senorami, custodiat a l'Arxiu-Biblioteca dels Franciscans de Catalunya ${ }^{7}$. L'accés musical a l'aplec es veu dificultat per la tabulatura utilitzada, un mètode de notació musical, probablement pensat per a arpa, segons un sistema que deixa a l'aire molts interrogants sobre la seva transcripció, en especial els aspectes rítmics. Algun estudi, emperò, n’ha provat una aproximació (Alicart 2012).

Al foli 43r del manuscrit Senorami, precisament abans d'una de les sardanes -«La Pistola»-, apareix una melodia amb l'epígraf «Corriente francesa por la A. La Ministranda». L'ús d'una tabulatura que deuria ser d'ús personal i l'absència d'indicacions rítmiques tornen prou compromès qualsevol assaig de transcripció de l'esmentada tonada, però l'epígraf almenys dóna alguna pista: la Ministranda és una courante i, per tant, una dansa d'origen francès, de ritme ternari i més aviat pausat.

Finalment, Ditxosos y bumils pastors també porta la indicació «al to de madama de Ricort», insistent a quatre dels manuscrits on s'ha transmès. De moment les recerques per recuperar aquesta tonada no han donat resultat.

De les sis lletres per a cantar «al to de», per tant, se'n podrien recuperar musicalment fins a cinc -tot i que demanaria una certa creativitat per part dels intèrprets, val a dir-ho-. No es pot afirmar, tanmateix, que les tonades fossin elegides pel mateix Fontanella, tot i que gran part de les músiques triades semblen coetànies i s'adapten amb naturalitat als seus poemes. A més, la presència de Joan Cererols al seu Vexamen indica una certa proximitat amb els músics del seu temps.

7 Arxiu-Biblioteca dels Franciscans de Catalunya, Manuscrits, 5C-16. 


\section{Josep Pujol i Coll. Ressonàncies musicals en l'obra de Fontanella}

\section{Bibliografia}

Alicart García, X. (2012) El llibre Senorami. Un manuscrit únic de música profana a la Catalunya del segle XVII, Treball de màster dirigit per A. Boadas, Barcelona, Universitat Ramon Llull, Facultat de Filosofia.

Balanza i González, F. (1985) «Joan Cererols (1618-1680)», Actes del I Symposium de Musicologia Catalana: Joan Cererols i el seu temps, Barcelona, Institut d'Estudis Catalans, pp. 25-76.

Bègue, A. (2001) «La primera réplica en los villancicos dialogados de José Pérez de Montoro», Criticón, 83, pp. 133-146.

Brown, K. (1987) «Context i text del vexamen d'acadèmia de Francesc Fontanella» Llengua \& Literatura, 2, pp. 173-252.

Estrada, G. (1981) «Introducció», Joan Cererols : Obres completes, V. Montserrat, Departament de Cultura i Mitjans de Comunicació de la Generalitat de Catalunya (col. Mestres de l'Escolania de Montserrat, IX).

Fontanella, F. (2017) Obra poètica completa de Francesc Fontanella, edició crítica electrònica, a càrrec de Valsalobre, P./Sogues, M. (coord.), Rossich, A/Miralles, E./Castaño, M./Garcia Busquets, A./Zaragoza, V./Figueras, N., Girona, Servei de Publicacions de la Universitat de Girona. Disponible a: http://www.nise.cat/BibliotecaDigital/Autors/FrancescFontanella.aspx

Lambea Castro, M./Josa, L. (2005) Libro de tonos bumanos (1655-1656), vol. 3, Barcelona, Consejo Superior de Investigaciones Científicas.

Lambea, M./Josa, L./Valdivia, F. (2012) Nuevo Íncipit de Poesía Musicada (NIPEM). Biblioteca Virtual Miguel de Cervantes. Disponible a: <http://hdl.handle.net/10261/30826>.

Knighton, T./Torrente, Á. (Eds.) (2007) Devotional Music in the Iberian World, 1450-1800: The Villancico and Related Genres, Aldershot, Ashgate Publishing.

Miró, M. M. (1995) La poesia de Francesc Fontanella (2 vol.), Barcelona, Curial.

Pujol Coll, J. (2016) Els vilancets 'de negre' al segle XVII. Tesi doctoral, Universitat Autònoma de Barcelona, Departament d'Art i de Musicologia. Disponible a: <http://www.tdx.cat/ handle/10803/383042>

Russell, C. H. (1999) «Marizápalos», dins Diccionario de la Música Española e Hispanoamericana, 7, pp. 194-95. 